Journal of Patient-Centered

$11-3-2014$

\title{
What Is PFAPA and Why Does it Matter?
}

Dennis J. Baumgardner

Follow this and additional works at: https://aah.org/jpcrr

Part of the Diagnosis Commons, Immune System Diseases Commons, and the Pathological Conditions, Signs and Symptoms Commons

\section{Recommended Citation}

Baumgardner DJ. What is PFAPA and why does it matter? J Patient Cent Res Rev. 2014;1:161-163. doi: 10.17294/2330-0698.1036

Published quarterly by Midwest-based health system Advocate Aurora Health and indexed in PubMed Central, the Journal of Patient-Centered Research and Reviews (JPCRR) is an open access, peer-reviewed medical journal focused on disseminating scholarly works devoted to improving patient-centered care practices, health outcomes, and the patient experience. 


\section{What Is PFAPA and Why Does it Matter?}

Dennis J. Baumgardner, MD, Editor-in-Chief | Editorial

In this issue of Journal of Patient-Centered Research and Reviews, the article by Dr. Jillian Hudson discusses several evidence-based treatments for the common ambulatory care problem of recurrent aphthous stomatitis (RAS). ${ }^{1}$ RAS, as the author points out, is a highly prevalent disease with unknown etiology and no definitive treatment. Canker sores (aphthous stomatitis) are like headaches and heartburn, common conditions often disregarded unless one or a loved one is suffering with them. We at Journal of Patient-Centered Research and Reviews encourage further submissions on common health problems that disrupt patients' daily activities. When I read Dr. Hudson's article, I decided to take editorial prerogative and write about a condition related to RAS, and how the condition affects one patient in particular.

The condition is called PFAPA, and the patient is our son.

This uncommon disease, which involves recurrent oral aphthae, is the syndrome of periodic fever, aphthous stomatitis, pharyngitis and cervical lymphadenitis, typically abbreviated to PFAPA syndrome. Our special needs child has had approximately 75 bouts of this vexing disorder. At age 12, he began having episodes of fever, aphthous stomatitis, pharyngitis and cervical adenopathy as well as other nonspecific symptoms every 3 to 5 weeks. At first, understandably, it was a diagnostic dilemma, and these episodes were diagnosed as aphthous stomatitis plus pharyngitis or otitis media or sinusitis. Antibiotics were usually given. After several recurrences, there was sufficient clinical evidence to diagnose PFAPA. Having a diagnosis certainly reduced the anxiety around these episodes but did not diminish the disappointment and annoyance of unexpected missing of school, extracurricular activities or vacations.

The PFAPA syndrome was first proposed by Marshall and colleagues in $1987^{2}$ and its clinical features further described in the 1990 s and early $2000 \mathrm{~s},{ }^{3-9}$ culminating in two comprehensive reviews $\mathrm{s}^{10,11}$ and one recently published large case series. ${ }^{12}$ These clinical features are summarized in Table 1. Malaise, irritability and fatigue may occur as part of a prodrome. ${ }^{11}$ Short episodes of illness recur regularly for several years, often "like clockwork" (typically at intervals between 3 and 6 weeks, depending on the individual), and alternate with healthy periods between the episodes. The classic diagnostic criteria used for PFAPA include regularly
Table 1. Features and symptoms of patients with periodic fever, aphthous stomatitis, pharyngitis and cervical lymphadentitis (PFAPA syndrome) $)^{8,10-12}$

\begin{tabular}{lc}
\hline Feature/symptom & $\begin{array}{c}\text { Range of frequency among } \\
\text { patient populations analyzed }\end{array}$ \\
\hline Mean age of onset & $2-5$ years \\
Male $1,5,8,9,22$ & $55-71 \%$ \\
Mean duration, each & $3-5$ days \\
Fever & Up to $100 \%$ \\
Fatigue (prodrome) ${ }^{8}$ & $62 \%$ \\
Pharyngitis & $65-100 \%$ \\
Cervical adenopathy & $61-100 \%$ \\
Aphthous stomatitis & $38-75 \%$ \\
Chills & $61-80 \%$ \\
Headache & $18-70 \%$ \\
Abdominal pain & $18-65 \%$ \\
Diarrhea & $10-30 \%$ \\
Arthralgias & $11-44 \%$ \\
Rhinorrhea & $18-33 \%$ \\
Cough & $20-28 \%$ \\
Rash & $4-22 \%$ \\
\hline
\end{tabular}

recurring fevers with onset at an early age ( $<5$ years) and constitutional symptoms, in the absence of upper respiratory infection, with at least one of the following clinical signs: 1) aphthous stomatitis, 2) cervical lymphadenitis, 3) pharyngitis, 4) exclusion of cyclic neutropenia, and 5) completely asymptomatic interval between episodes accompanied by normal growth and development. ${ }^{6}$ While earlier publications suggested that symptom onset must occur by age 5 for diagnosis of PFAPA, ${ }^{2,6}$ onset of signs and symptoms otherwise consistent with PFAPA beyond the age of 5 was reported in 18 of 105 cases in a more recent case series. ${ }^{8}$ In addition, other studies have reported onset of PFAPA in older children ${ }^{13}$ and adults. ${ }^{14}$ Nonetheless, symptoms frequently begin before age 5 and continue through adolescence. There is sometimes a family history of PFAPA, especially in persistent cases. ${ }^{11}$

The etiology of PFAPA is still unknown, but it is now considered one of the "autoinflammatory fever disorders." 11 A genetic component has been hypothesized ${ }^{15}$ but not yet established. Diverse ancestry among PFAPA patients was noted in one study. ${ }^{8}$ Other similar syndromes, such as familial Mediterranean fever, hyperimmunoglobulinemia 
D syndrome with fever (abbreviated HIDS and commonly known as hyper-IgD syndrome), cyclic neutropenia, tumor necrosis factor receptor 1-associated syndrome and mevalonate kinase deficiency, are differential diagnoses of PFAPA. ${ }^{10,11,16}$ Diagnosis of PFAPA is made on clinical grounds and exclusion of similar syndromes. There is no specific diagnostic laboratory test, although a number of inflammatory markers are elevated during the febrile episodes. ${ }^{10,11}$ Also, specific genetic tests will often rule out the aforementioned differential diagnoses and other related entities. ${ }^{8,10,11,16}$ Despite sharing common characteristics, familial Mediterranean fever episodes are not periodic and predictable like PFAPA episodes. ${ }^{6}$ Although hyper-IgD syndrome has recurrent fever, rash, abdominal symptoms and elevated serum IgD levels, it does not display PFAPA's periodic febrile pattern. ${ }^{6}$ Cyclic neutropenia probably most closely mimics PFAPA syndrome, however, the presence of complicating infections and neutropenia are not observed in PFAPA, and the fever of cyclic neutropenia does not abate with corticosteroids. ${ }^{6,11}$ In fact, prompt relief of symptoms on administration of glucocorticoids like prednisone ${ }^{10,11}$ is one of the best diagnostic clues for PFAPA.

The natural history of PFAPA generally includes some degree of chronicity, however, episodes often get less intense and less frequent with age., ${ }^{2,3}$ Interestingly, some parents have noticed fewer PFAPA episodes in their children during summer months and that affected children seem to be less prone to common respiratory and gastrointestinal viral syndromes. ${ }^{8}$ Spontaneous resolution rates vary between $20 \%$ at a mean follow-up of 33 months $^{8,10}$ and $49 \%$ (46/94) in those followed for more than 12 months, although 15 of these 46 had tonsillectomy. ${ }^{12}$ Our son, now 20 years old, has not enjoyed spontaneous resolution of this disorder, but he has experienced less intensity with many of the episodes, likely due in part to use of single-dose prednisone. We sometimes still forget that a day of lassitude likely indicates an impending "mouth sore."

Regarding treatment, single-dose prednisone $(1-2 \mathrm{mg} / \mathrm{kg})$ has proved effective ( $84-99 \%$ response rate) $)^{8,9,17}$ for resolving the fever of PFAPA episodes within a few hours. However, other symptoms are slower to resolve. Unfortunately, corticosteroids do not prevent further episodes and may shorten the interval between episodes. ${ }^{8,11}$ Cimetidine treatment was purported to be effective in inducing remission and preventing future onset of PFAPA episodes, however, it reportedly helps less than $30 \%$ of patients ${ }^{8,11}$ and was not considered efficacious in a recent meta-analysis. ${ }^{17}$ Colchicine has shown variable response in small studies. ${ }^{10,11}$
Tonsillectomy is another treatment option, but a controversial one, partly due to the heterogeneity seen in published studies, though mainly due to the added risk of surgery for a disease that often spontaneously resolves. ${ }^{10-12,18}$ Tonsillectomy, with or without adenoidectomy, was found effective in both the meta-analysis by Peridis et al. ${ }^{17}$ and a 2010 Cochrane review (number needed to treat $=2$ ).${ }^{18}$ In a recently reported prospective case series of 124 patients (ranging in age from 18 months to 18 years) with carefully diagnosed PFAPA who were treated with tonsillectomy and adenoidectomy, 102 patients were followed for a mean of 43 months. Within this cohort, 99 of 102 patients had prolonged symptom resolution immediately after the procedure. ${ }^{16}$

What is the difference between PFAPA and the subject of Dr. Hudson's paper, RAS? The latter, taken apart from PFAPA, is probably a heterogeneous syndrome. ${ }^{19}$ Up to $40 \%$ of individuals in the United States have a history of RAS-like disease ${ }^{20}$ though symptoms such as recurrent fever or pharyngitis are not observed. ${ }^{21}$ Initially, new-onset PFAPA episodes could be misdiagnosed as individuals with RAS having concurrent pharyngitis or other upper respiratory tract infections. This misdiagnosis could result in unnecessary antibiotic prescriptions. A population-based series in Norway of 46 children with PFAPA (calculated annual incidence rate of 2.3/10,000 children up to age 5 years) noted that $55 \%$ had received antibiotics during five or more PFAPA episodes. ${ }^{22}$ We studied 353 randomly selected cases of childhood aphthous stomatitis from our institution's data warehouse (2002-2007); 47 of 353 (13\%) were documented to be recurrent (at least two episodes in one year). Only two (0.6\%) had PFAPA, consistent with this entity being rare in a community population. Antibiotics were prescribed in only $4 \%$ of all aphthous stomatitis cases without other diagnosis. ${ }^{23}$

Lastly, despite it being an uncommon disease, PFAPA has become an area of active research. A study of 15 patients in Europe has detailed a variety of inflammatory markers that are increased during PFAPA febrile episodes only. The data suggest that monocyte production of interleukin (IL)-1 beta is dysregulated in patients with PFAPA. ${ }^{24}$ Similarly, a study of 18 patients showed polymorphonuclear neutrophils (PMNs), serum amylase A, and C-reactive protein are elevated in PFAPA patients when febrile, but not when afebrile. Also, PMNs from these patients have alterations in apoptosis, priming and intracellular oxidative bursts, especially during febrile attacks, when compared to febrile controls..$^{25}$ A prospective study of 124 PFAPA patients in Israel revealed that $52 \%$ had Mediterranean fever gene 
(MEFV) mutations. Compared to those without mutations, the patients with mutations, by an unknown mechanism, had shorter duration of febrile attacks and needed lower corticosteroid doses to abort attacks. ${ }^{26}$ Again, the underlying etiologies of the significant changes that lead to, or result from, febrile attacks in those with PFAPA is unclear.

The findings and discussion of a recently reported study of six patients is fascinating. The authors concluded from their data that febrile PFAPA episodes are the result of environmentally triggered disordered IL-1 and complement activation leading to chemokine release and retention of activated T-cells in peripheral tissue. Five patients were treated with a recombinant IL-1 receptor antagonist, with prompt favorable clinical and biomarker responses. ${ }^{27}$

In summary, PFAPA is a rare and vexing, but very interesting disease. Hopefully, the aforementioned recent basic and sentinel clinical research will translate to patient-friendly treatments for patients who suffer from this particular entity as well as for victims of related episodic fever disorders ${ }^{28}$ and perhaps other disorders of episodic immune dysregulation such as recurrent aphthous stomatitis.

\section{Acknowledgment}

The author thanks Michael H. Farrell, MD, of Aurora Health Care for manuscript suggestions.

\section{References}

1. Hudson J. Recurrent aphthous stomatitis: diagnosis and management in primary care. J Patient-Centered Res Rev. 2014;1:197-200.

2. Marshall GS, Edwards KM, Butler J, Lawton AR. Syndrome of periodic fever, pharyngitis, and aphthous stomatitis. J Pediatr. 1987;110:43-6

3. Tasher D, Somekh E, Dalal I. PFAPA syndrome: new clinical aspects disclosed. Arch Dis Child. 2006;91:981-4.

4. Feder HM Jr, Bialecki CA. Periodic fever associated with aphthous stomatitis, pharyngitis and cervical adenitis. Pediatr Infect Dis J. 1989;8:186-7.

5. Galanakis E, Papadakis CE, Giannoussi E, Karatzanis AD, Bitsori M, Helidonis ES. PFAPA syndrome in children evaluated for tonsillectomy. Arch Dis Child. 2002;86:434-5.

6. Thomas TK, Feder HM Jr, Lawton AR, Edwards KM. Periodic fever syndrome in children. J Pediatr. 1999;135:15-21.

7. Padeh S, Brezniak N, Zemer D, et al. Periodic fever, aphthous stomatitis, pharyngitis and adenopathy syndrome: clinical characteristics and outcome. J Pediatr. 1999;135:98-101.

8. Feder HM, Salazar JC. A clinical review of 105 patients with PFAPA (a periodic fever syndrome). Acta Paediatr. 2010;99:178-84.

9. Wurster VM, Carlucci JG, Feder HM Jr, Edwards KM. Long-term follow-up of children with periodic fever, aphthous stomatitis, pharyngitis, and cervical adenitis syndrome. J Pediatr. 2011;159: 958-64.
10. Caorsi R, Pelagatti MA, Federici S, Finetti M, Martini A, Gattorno M. Periodic fever, apthous stomatitis, pharyngitis and adenitis syndrome. Curr Opin Rheumatol. 2010;22:579-84.

11. Vigo G, Zulian F. Periodic fevers with aphthous stomatitis, pharyngitis and adenitis (PFAPA). Autoimmun Rev. 2012;12:52-5.

12. Król P, Böhm M, Sula V, et al. PFAPA syndrome: clinical characteristics and treatment outcomes in a large single-centre cohort. Clin Exp Rheumatol. 2013;31:980-7.

13. Lee WI, Yang MH, Lee KF, et al. PFAPA syndrome (Periodic Fever, Aphthous stomatitis, Pharyngitis, Adenitis). Clin Rheumatol. 1999;18:207-13.

14. Padeh S, Stoffman N, Berkun Y. Periodic fever accompanied by aphthous stomatitis, pharyngitis and cervical adenitis syndrome (PFAPA syndrome) in adults. Isr Med Assoc J. 2008;10:358-60.

15. Akelma AZ, Cizmeci MN, Kanburoglu MK, et al. Is PFAPA syndrome really a sporadic disorder or is it genetic? Med Hypotheses. 2013;81:279-81.

16. Licameli G, Lawton M, Kenna M, Dedeoglu F. Arch Otolaryngol Head Neck Surg. 2012;138:902-6.

17. Peridis S, Pilgrim G, Koudoumnakis E, Athanasopoulos I, Houlakis M, Parpounas K. PFAPA syndrome in children: A meta-analysis on surgical versus medical treatment. Int $J$ Pediatr Otorhinolaryngol. 2010;74:1203-8.

18. Burton MJ, Pollard AJ, Ramsden JD. Tonsillectomy for periodic fever, aphthous stomatitis, pharyngitis, and cervical adenitis syndrome (PFAPA). Cochrane Database Syst Rev. 2010;9:CD008669.

19. Preeti L, Magesh K, Rajkumar K, Karthik R. Recurrent aphthous stomatitis. J Oral Maxillofac Pathol. 2011;15:252-6.

20. Zunt SL. Recurrent aphthous stomatitis. Dermatol Clin. 2003;21:33-9.

21. Jurge S, Kuffer R, Scully C, Porter SR. Recurrent aphthous stomatitis. Oral Dis. 2006;12:1-21.

22. Førsvoll J, Kristoffersen EK, Øymar K. Incidence, clinical characteristics and outcome in Norwegian children with periodic fever, aphthous stomatitis, pharyngitis and cervical adenitis syndrome: a population-based study. Acta Paediatr. 2013;102: 187-92.

23. Ranade M, Baumgardner DJ, Banerjee I, Doniparthi M. Prevalence of periodic fever, apthous stomatitis, pharyngitis, and cervical adenitis syndrome (PFAPA): Eastern Wisconsin. (abstr.) http://ebookbrowsee. net/baumgardner-pfapa-poster-pdf-d352953360. Accessed July 15 , 2014.

24. Kolly L, Busso N, von Scheven-Gete A, et al. Periodic fever, aphthous stomatitis, pharyngitis, cervical adenitis syndrome is linked to dysregulated monocyte IL- $1 \beta$ production. J Allergy Clin Immunol. 2013;131:1635-43.

25. Sundqvist M, Wekell P, Osla V, et al. Increased intracellular oxygen radical production in neutrophils during febrile episodes of periodic fever, aphthous stomatitis, pharyngitis, and cervical adenitis syndrome. Arthritis Rheum. 2013;65:2971-83.

26. Berkun Y, Levy R, Hurwitz A, et al. The familial Mediterranean fever gene as a modifier of periodic fever, aphthous stomatitis, pharyngitis, and adenopathy syndrome. Semin Arthritis Rheum. 2011;40:467-72.

27. Stojanov S, Lapidus S, Chitkara P, et al. Periodic fever, aphthous stomatitis, pharyngitis, and adenitis (PFAPA) is a disorder of innate immunity and Th1 activation responsive to IL-1 blockade. Proc Natl Acad Sci U S A. 2011;108:7148-53.

28. Frenkel J, Kuis W. Overt and occult rheumatic diseases: the child with chronic fever. Best Pract Res Clin Rheumatol. 2002;16:443-69.

(C) 2014 Aurora Health Care, Inc. 